Marquette University

e-Publications@Marquette

College of Nursing Faculty Research and

Publications

Nursing, College of

$1-1-2008$

Crossing Borders in Search of the MotherDaughter Story: Interdependence Across Time and Distance

Ruth Belknap

Marquette University, ruth.belknap@marquette.edu

Published version. Families in Society, Vol. 89, No. 4 (2008): 631-639. DOI. (C) 2008 Alliance for Children and Families. Reprinted with permission from Families in Society (www.FamiliesInSociety.org), published by the Alliance for Children and Families. 


\title{
Crossing Borders in Search of the Mother-Daughter Story: Interdependence Across Time and Distance
}

\author{
Ruth Ann Belknap
}

\begin{abstract}
Although studies have identified the importance of the mother-daughter relationship and of familism in Mexican culture, there is little in the literature about the mother-daughter experience after daughters have migrated to the United States. This study explores relationships between three daughters in America and their mothers in Mexico, and describes ways in which interdependence between mothers and daughters can be maintained when they are separated by borders and distance. Data collection included prolonged engagement with participants, field notes, and tape-recorded interviews. Narrative analysis techniques were used. Findings suggest mother-daughter interdependence remains. Some aspects may change, but the mother-daughter connection continues to influence lives and provide emotional and, to a lesser extent, material support in their lives.
\end{abstract}

n January 2003, the United States Census Bureau reported that Hispanics had become the largest minority group in the country (Associated Press, 2003). This is due in large part to the unprecedented rate of immigration from Latin America and Mexico. Migration from Mexico is largely an adaptive strategy used in response to the economic crisis in Mexico (Durand \& Massey, 2004). The majority of these migrants plan to return home. However, the tightening and increased militarization of the United States-Mexican border has made undocumented border crossing more difficult and dangerous. This has resulted in increased length of stay, more women and children in migration, and an increase in the population of undocumented persons on the United States side of the border (Durand \& Massey, 2004). Literature on Mexican migration is extensive. However, little research has focused on female migration and specific gender issues (Jones, 2002).
In the course of my clinical experience counseling immigrant women at a rural domestic violence agency and conducting research with women from Mexico, I have listened to the stories of the lives of women who have migrated here from Mexico (Belknap \& Sayeed, 2003). These women experience a number of challenges including difficulties communicating with language, accessing health care, and understanding a variety of bureaucracies and systems, as well as inadequate education, insufficient wages, discrimination, and too much or too little work. I often hear in women's voices a longing for connection and support, or relief that at last a connection has been made, a friend found, a relationship with a supportive cultural liaison initiated, or, most importantly, a mother has arrived from Mexico for a visit. The women speak of the influence of their mothers in their lives as well as the need to move forward for their own children. Although 
studies have identified lack of support as predictive of depression and the importance of familism (face-to-face interaction or supportive behaviors) in Mexican culture (Vega, 1990), there is very little in the literature about the mother-daughter experience and the importance of this relationship in Mexican women's lives. The purpose of this study is to explore the relationships of three motherdaughter dyads across borders. A description of how mother-daughter interdependence is maintained across borders is developed.

\section{Background}

Research on the importance of the mother-daughter relationship in families of Mexican descent is beginning to appear in the literature. Studies of cross-cultural comparisons of adult daughter perceptions of the motherdaughter relationship found that for Mexican American women, the mother-daughter relationship focuses on honest, open communication and doing things together. Furthermore, emotional and practical intimacies are valued, and distance may hinder the relationship (Rastogi, 2002; Rastogi \& Wampler, 1999).

Maternal support has been shown to be important during pregnancy for Mexican immigrant women. Sherraden and Barrera (1996) analyzed the key role that a woman's own mother plays during pregnancy. Their findings indicate that women whose mothers were available and supportive during pregnancy were less likely to have low-birth-weight babies. Laganá (2003), in examining the influence of acculturation on pregnancy beliefs and practices, found that Mexican American women identified their mothers as their strongest source of social support during pregnancy.

Maternal identification has a positive influence on identity and body image in adolescents of Mexican descent in the United States. Marsiglia and Holleran (1999) used narrative analysis to examine how Chicana adolescents establish and maintain identity. In their study, Chicana adolescents identified their mothers as their strongest role models and indicated that they draw strength from their families, especially their mothers. Hahn-Smith and Smith (2001) compared the positive influence of maternal identification on body image, eating attitudes, and self-esteem in Hispanic and Anglo girls in New Mexico. Girls who aspired to be like their mothers had higher levels of self-esteem and lower levels of eating disorders. These studies support the notion that mother-daughter relationships are central in the healthy development of Mexican American girls.

No studies about mother-daughter relationships across the United States and Mexican border were located. However, a frequent theme in the findings of an ethnographic study of kinship ties along a 60-mile stretch of the border was that women on both sides rely on kin for social and psychological support (Bastida, 2001). Mutual support between mothers and adult children was specifically identified as an important source of support.

\section{Purpose}

The purpose of this study is to explore the nature of the mother-daughter relationship across borders from the perspectives of three women who, as adults, migrated to the United States, and their mothers, who remain in Mexico. The dimensions of mother-daughter interdependence across time and space are then described.

\section{Conceptual Framework}

Relationships within Latino families can best be understood through the lens of familismo. This construct describes the senses of belonging, solidarity, family pride, and loyalty that are present in Latino families (Falicov, 2001). Familismo designates flexible nuclear family boundaries and suggests collectivism or interdependence in family function (Falicov, 1998). Family boundaries expand easily, both vertically and horizontally. Whereas intergenerational nuclear families are typical in Mexico (grandparents, parents, children), families who are recent immigrants to the United States commonly expand horizontally (siblings, cousins, family friends).

Collectivism and interdependence describe the shared way in which family functions-such as caretaking of children and elders, finances, and emotional supportare accomplished (Falicov, 1998). How interdependence is maintained across time and space is of primary interest in this study. The domains of inquiry for this study are the mother-daughter relationship and interdependence. The research questions are: What is the nature of the relationship between mothers in Mexico and their adult daughters who have migrated to the United States? How is interdependence maintained across borders? How does interdependence after migration differ from that experienced prior to migration?

\section{Method}

This descriptive study involved prolonged engagement with the daughters in the study in their receiving communities in the rural Midwestern United States as well as during trips to Mexico to visit their mothers and sending communities. Data collected included field notes, photographs of the communities, and tape-recorded interviews.

\section{Participants}

A purposive sample of three mother-daughter dyads was recruited. At the conclusion of the sixth interview, it was determined that data from the three dyads contained 
sufficient redundancy in the narrative to conclude participant recruitment. The daughters were women who had migrated to the United States after the age of 15 and had resided here from 3 to 14 years. I had come to know two of these women through a support group for women having relationship problems. The women in this group struggled with a variety of issues including difficulties with relocation adjustment, insufficient household income, impediments to accessing health care services, and problems with relationships. The third woman I knew more informally. I functioned as a cultural liaison to assist her with transportation and negotiation of health care and social systems. Prior to the individual interviews, the women asked their mothers if they would be willing to participate and be interviewed. All of the mothers readily agreed. Inclusion criteria were as follows: women who had migrated from Mexico and were living in rural Midwestern United States areas, who were 15 or older at the time of migration, and who had mothers living in Mexico who also were willing to participate in the study. Participants were monolingual Spanish speakers (for demographic data, see Table 1).

\section{Setting and Data Collection}

During data collection in Mexico, I resided in towns two to three hours from the homes of the study participants. In both towns I lived with families who were not related

TABLE 1. Demographics of Study Participants

\begin{tabular}{lcccc}
\hline & AGE & $\begin{array}{c}\text { \# OF } \\
\text { CHILDREN }\end{array}$ & $\begin{array}{c}\text { YEARS OF } \\
\text { EDUCATION }\end{array}$ & $\begin{array}{c}\text { How LONG HAS IT BEEN } \\
\text { SINCE YOU SAW YOUR } \\
\text { MOTHER/DAUGHTER? }\end{array}$ \\
\hline Madre 01 & 44 & 5 & 2 & 3 years \\
Madre 02 & 56 & 7 & $8^{*}$ & 10 years \\
Madre 03 & 70 & 13 & 0 & 8 years \\
Hija 01 & 21 & 2 & 6 & 3 years \\
Hija 02 & 36 & 4 & 9 & 10 years \\
Hija 03 & 43 & 4 & 2 & 8 years \\
\hline
\end{tabular}

* Plus nursing certificate.

TABLE 2. Interview Prompts to the participants. Time spent in Mexico was two weeks at one site and three weeks at the other. Time spent with the mothers consisted of one visit of one day with Madres (mothers) 01 and 02 and, because of the remote location of her home, two visits of one day each (one interview) with Madre 03.

Institutional review board approval was obtained prior to the start of data collection. Informed consent was obtained from each participant prior to each interview. Interview guides (Table 2) were utilized; however, interviews were not strictly structured. Data collection with daughters took place in two rural communities located near each other in the Midwestern United States. Mothers were interviewed in two rural communities in two different states in Mexico.

I am of European descent. I have basic Spanish conversation skills and have developed Spanish literacy skills that enable me to read and translate written text. In order to facilitate the interview process, interviews were conducted with the assistance of bilingual, bicultural interpreters who helped clarify complex points and provided brief summaries when needed. The interpreters in Mexico were not individuals known by the women. The interviews in Mexico took place in the participant homes. Other female family members (granddaughters, daughters, and daughters-in-law) were invited by the participants to be present, but they did not participate in the interviews. An interpreter was used for two of the interviews in the United States. She was known to the participants, and the interviews took place in her kitchen. The third interview was conducted in the participant's home with no interpreter present. In all cases in the United States, small children were playing in adjacent rooms and no other adults were present. Interviews were recorded.

\section{Data Analysis}

Recordings were transcribed verbatim by a bilingual, bicultural transcriptionist. The first reading consisted of listening to each recording while reading along with the Spanish text. During this reading, changes in tone of voice, laughter, and crying were noted on the transcript.
MOTHER INTERVIEW

\footnotetext{
Tell me about your daughter.

What words do you use to describe your relationship with your daughter?

Tell me about how you advised your daughter when she lived in Mexico? How has that changed now that your daughter lives in the United States? How do you advise her now?

Tell me about the support you gave your daughter when she was here. How do you support her now? In what ways does your daughter support you?

What important lessons did you teach your daughter?
}

DAUGHTER INTERVIEW

Tell me about your mother.

What words do you use to describe your relationship with your mother?

How did your mother advise you when you lived in Mexico? How does she advise you now? What has changed?

Tell me about the support your mother gave you in Mexico, and the support she gives you now. How do you support her?

What important lessons did you learn from your mother? If I could meet your mother, what would you like me to ask her? 
A brief summary of the general tone of each narrative was written, including key or repetitive phrases. Blocks of text to be translated were identified in the second reading. The data were translated by the researcher and bilingual research assistants. All translations done by the researcher were evaluated for accuracy by a bilingual/ bicultural research assistant. The transcripts were read a third time in Spanish and English. At this point, four key themes were identified: emotional support, material support, connection with mother/daughter maintained, and connection with mother/daughter disrupted.

In the next level of analysis, passages related to each of the initial themes, as well as passages that offered important cultural or relational information but were not easily coded into any of the four identified themes, were identified. In order to capture nuance that might otherwise be lost in translation, this step of the analysis proceeded by working back and forth between the original Spanish text and the English translations and by color-coding the themes in both the English and Spanish texts. Summaries of thematic content were then written for each interview. Next, the summaries were read by the researcher as mother-daughter dyads, and notations were made of the similarities and differences in the narratives about each specific mother-daughter relationship and the overarching theme in each narrative dyad was identified. Summaries were then regrouped, daughters in one group and mothers in another, and were read a final time for recurring themes. Themes occurring across narratives were identified after the two final readings.

\section{Findings}

Each narrative dyad had a distinct overarching theme that described the mother-daughter bond. The three distinct relationship themes of the mother-daughter bond are identified here as nurturance, communication, and shared work. Two themes, connection and support, were identified as occurring across narratives.

Hijas (daughters) 01 and 02 live in the same rural community in the United States. They come from the same unmapped pueblo in central Mexico. To find it, we drove to a slightly larger nearby community and asked how to reach La Paz (not the real name). We were directed to follow gravel roads. The daughters had told us to "ask anyone on the street for the home of either of the mothers and they will tell you how to find them." The interviews took place in their respective homes. In traditional Mexican fashion, after the interviews we enjoyed a wonderful meal prepared by the participants and their families.

\section{Mother-Daughter Bond as Nurturance}

We entered the home of Madre 01 through a white iron gate that led to a small garden courtyard. It was a modest home; the walls of the room were a vibrant blue. She was expecting us; six straight-back chairs were arranged facing one another. The garden was visible through the open door, and street noises and bird sounds drifted in. After greetings, introductions, and offers of soda to drink, the interview began with the prompt "Digame sobre tu hija" (“Tell me about your daughter").

Nurturance emerged as the overarching theme in the narratives from mother-daughter Dyad 01. In the tapes of both the mother and daughter interviews, the woman was crying as she began to speak. Madre 01 started her narrative by saying she loved her daughter very much. Then she described how unhappy her daughter was in the United States because she was lonely and so far away. She didn't want to go, but her husband made the decision they would migrate to the United States:

I also get sad because she's not happy. But what can I do? She got married and she has to follow her husband. But [she doesn't agree] because her husband doesn't do things for her ... since now she is pregnant and she says that her husband doesn't help her. That is why she says that it would be better to come back here so that I can help her. And I tell my daughter, "No, you have to be with him." Well, what can we do about it? (Madre 01)

Hija 01 also began her narrative by telling us about her loneliness:

Tell me about your mother. What is she like? Very caring, a very good person. She always has many friends. At the house, always many people would visit her. And I believe it is because of this that I feel so alone. Her sisters always were there, eating ... always eating together. If someone did not eat, she would feed them later on. She shared.

Hija 01 described her mother as a nurturer. She nurtured with food and friendship. This daughter had been away from her mother for three years. It is the material support she received from her mother in Mexico that she most longed for in the United States. She was pregnant with her third child, and she described the contrast between the birth of her first child in Mexico and the second in the United States.

When I was pregnant with [my first baby], I felt badly and she [mother] didn't let me do anything. I was with her at home [crying as she is talking]. She did everything. She gave me food, and I don't know. When I feel bad, I remember or think how it was with her 
and I think if I was with her, I would not feel as bad. Later she gave me something so that I don't feel so bad. I don't know, I don't feel comfortable here. When your first son was born, your mother was there? Yes, she was there and he was born and I went home with her. She took care of me. They took care of us for 40 days. She took care of me. They gave us food, like chicken, they made food for us. They took care of my son ... we weren't able to go out of the house. I was weak and they gave us food like oatmeal and bread, things like that. And here, no, when I had [my second baby], I came home from the hospital and I had to clean the house because it was really bad. And no, I was alone, because I had to do things and, I don't know, I missed her very much. I felt very alone. And now at times, still, when it is around five in the afternoon, I feel very alone. (Hija 01)

Although the content of the daughter's narrative was not known by the mother, her mother expressed concern around this same issue:

Yesterday she called me and told me that she is pregnant again and that she goes out with her husband, but that he doesn't help her and he just leaves with his friends. She says, "It would be better if you came here." I say, "How am I going to go there?" I tell her, "If I could come, I would be there already to help you," but it's no good. (Madre 01)

Madre 01 was sad because her daughter was unhappy. This mother offered advice and verbal encouragement during their biweekly phone conversations. However, it was the physical nurturance she provided that her daughter craved. Over the miles, this mother used the phone to try to connect her daughter with others who could provide what she could not. She advised her daughter to attend the support group, meet older women, and talk to them as if they were her mother. "I told her to talk to someone older than she is, talk to her and confide in her just as if you were with me. And she says, yes" (Madre 01).

Throughout the interview with Madre 01, I felt very connected to her. Rapport was quickly and easily established as she spoke from her heart. Often she had difficulty responding to the interview prompts, so I would ask for a story or a memory about her daughter. This proved to be helpful. Her responses were spontaneous and, at times, tinged with sadness.

Mother-Daughter Bond as Communication of Love Hija 02 had been in the United States for 14 years. She returned to Mexico once several years ago, but now had not seen her mother for more than 10 years. The narratives from this mother-daughter dyad centered on how the mother and daughter communicated love. References to the ways in which the love they had for each other was communicated across distance were threaded throughout both of the narratives. Although this mother talked about sharing food with her daughter and supporting her by helping her economically when the daughter was in Mexico, the overarching theme in this narrative dyad was love.

Hija 02 began her interview with this description of her mother:

My mom is loving, understanding. She understands us. She supports us, and she is always saying caring words like, "I love you, you're beautiful," and she always tries to help people. She is always there whenever we need her. She is always there to listen to us. I love her a lot. And when I talk to her, it makes me feel a lot better. It feels good. She is a complete mother.

When asked what had changed in their relationship since she had come to the United States, Hija 02 responded as follows:

Nothing. At least, I think nothing. Since I have a lot of trust ... like ... communication lines are always open with her. Like ... how could I tell you ... it's like ... she says that when she hears my voice, it's like I'm there with her. I am not there, but she feels like I'm right there with her. And that's also how I feel. We are not very close in distance, but I feel like I'm right there with her. There are days that I just sit and realize that a lot of days have gone by. However, I think that our relationship has not changed at all.

Later in the interview, she spoke of learning about love from her mother's example:

I have learned so many things from her. How to love my children ... and something else that she taught us was how to love each other as siblings. She was always telling us when we were little. Did you know that back there we didn't have enough to buy a soda for each of us, so we had to buy one soda and share it among us? So there was always someone who said, "Hey look, he is drinking more than me," and she would say, "No, it's not good to be jealous because there is enough for everyone." (Hija 02)

The home of Madre 02 was large and reflected the economic support she received from her children, some of whom were in the United States. The large sala where the interview took place was painted a bright yellow, with a wall of glass looking out onto a small courtyard with plants and hummingbirds. This room was open to 
the upper level hall and was furnished with comfortable couches and chairs.

The interview with Madre 02 was the most formal of the interviews, reflecting the formality of this household. As we talked, one of her granddaughters appeared with a green-glazed terra cotta tray with glasses of Coke and a pink bowl with ice cubes and ice tongs. Madre 02 had no difficulty with the interview prompts and spoke for several minutes after each prompt.

When asked about changes in the relationship with her daughter, Madre 02 answered as follows:

The thing is that even when you are separated ... love doesn't go away. Just because you are separated doesn't mean that the love will be less for your daughter. You just have to feel as if you had your daughter here and talk to her on the phone and transmit the love to her so that she feels your love.... What has changed is just that I miss her, nothing more. I miss her, but the love that I feel for her stays the same.

\section{Mother-Daughter Bond as Shared Work}

The home in Mexico of mother-daughter Dyad 03 was very remote; this mother lived near the top of a mountain on the remains of a small coffee farm. The only way to reach her home was on foot. The surrounding vegetation was breathtaking: bananas, pineapples, and coffee beans grew wild along the dirt road. Mist hung in long, thick strands over the deep valleys. The road ended, and there was a steep climb up a mountain path to the home of Madre 03. She met us on the road and walked ahead of us. A sturdy 70-year-old woman, she had steady footing in spite of her plastic sandals. I struggled and slid on the rocks in my best hiking shoes. The house was very modest, una casa muy humilde, and sunlight peaked through the gaps in the wood siding. The kitchen was separated from the sala by a walkway, where a hen and her chicks pecked at a millipede in the corner. Through the open windows and door, I heard the river very far below. I saw and heard water dripping into a cistern edged with bright pink flowers in plastic pots. Madre 03 began cooking over an open fire in the corner of the cocina (kitchen). I had known the daughter of this woman for about five years-the daughter was a woman of few words, as was her mother. Yet, through the many hours we had spent together, I felt I had known this daughter quite well. It was immediately apparent why the daughter described her relationship with her mother primarily through the work they had shared. Here, the tasks of feeding and caring for a family consumed a woman's waking hours.

With the opening prompt, "Tell me about your mother," Hija 03 asked, "About her life?" and then she proceeded to answer:
She had 13 children ... 13, but 9 are alive, and 4 of them are in the cemetery .... She said that she suffered a lot, not like us, not anymore. Our lives have changed. It is not the same ... like when [we were] much smaller, my mom suffered a lot with us. Your mother suffered?

In the ranch, there was no light, there was no electricity. Here in the United States, we have everything-electricity, a micro, one does not make tortillas .... Her life was very difficult, especially when we were young. Now we are older. That is why life is so hard. Because of the jobs, it is harder, and here, no. Here in the United States, you have disposable diapers for the children. I raised my three kids. I washed diapers by hand ... . Over there, there you raise animals. Over there, the children drink cow's milk, goat milk. Not here, because here the children get milk from ... I go to the store to bring the milk in a gallon. Everything is in the fridge. Everything is easier.

When I asked this daughter what she and her mother talked about as they worked, she looked at me and smiled and said, "The work, we talked about the work." It was as if she were saying, "What else is there?" The support that flowed between these two women continued to be material in nature. The daughter supported her mother with small amounts of money and had purchased a home for the mother in a nearby pueblo. However, it was clear that the mother preferred her mountaintop home and tending to her chickens, sheep, and goats. The daughter said her mother supported her by keeping safe the photos and things she left behind. When the daughter needed medicine that could only be found in Mexico (certain herbs and syrups for a cough), her mother sent these things to her.

These three mother-daughter dyads described motherdaughter bonds that were unique with regard to the unifying aspect of each relationship. However, the themes of connection and support occurred across the narratives, indicating that interdependence may be found in a variety of relational styles. None of the mothers or daughters indicated their relationships had been weakened by the physical distance and border between them. Things had changed in some ways, but the bond between them remained.

\section{Mother-Daughter Interdependence}

Indicators of continuing mother-daughter interdependence were found in all of the narratives. The themes of connection and support occurred across the six narrative dyads.

Connection. "Talk to me and I'll be with you" (Madre 02). Connection, maintained through regularly scheduled phone conversations, was a consistent theme in the narratives. Each participant in the study mentioned how often she spoke with her mother or daughter. Hija 02 and 
Hija 03 had been in the United States for more than 10 years. They referred to their early years here as very difficult because telephones were not available in or near the homes of their mothers. Now Madre 02 had a phone in her home and Madre 03 used the phone in the caseta (small store in the front room of a home located in a small cluster of houses) at the foot of the mountain where she lived.

Madre 02 knew she would speak with her daughter about once a month. She said that if, for some reason, her daughter did not call, she called her. For mother-daughter Dyad 03, things were a bit more complicated. Madre 03 had to walk 20 minutes down the side of the mountain to reach the caseta. This mother and daughter connected by phone cada quince dias (every two weeks). Hija 03 had siblings in another community in the United States. The children of this mother had developed a system to alert one another to their mother's presence at the caseta. After one of them spoke to her, a telephone chain occurred; all the children knew that their mother was in the caseta, and all tried to call her.

For Hija 01, the lack of immediacy was described as a loss. She called her mother using prepaid phone cards. She said that sometimes she forgot something she wanted to say because time had elapsed between the event and the call. It was also difficult for her when she wanted to talk with her mother or ask advice but had to wait until she had the money to purchase another phone card.

Connections maintained across distance were evident when the transcripts were read as dyads. Descriptions by mothers of their daughters' lives were very similar to descriptions by daughters of their own lives. This was particularly interesting because all daughters and one mother said that, in an effort to prevent worry, they did not tell everything about their lives.

So she [mother] doesn't know that you are sad here? Yes, I tell her sometimes, but not in a way that was saying that. No, I don't say more than I want to go, but I don't cry. Because I think that, well, she would feel bad, or I don't know. (Hija 01)

I don't tell her anything, because if I told her about the problems I have, it would just give her more to be unhappy about. That is why I don't tell her anything. (Madre 01)

The transcripts provide evidence that Madre 01 was aware of her daughter's unhappiness. She knew that her daughter was unhappy and lonely because the daughter did not have help from her husband with the children. In return, Hija 01 was quite aware of the problems in her mother's life. When asked what kind of problems her mother had, Hija 01 said:
Things like, with my father, I don't know. My father always has been a drinker and very machista. He always wants things done right away-when he says. I don't know, always we would talk about this.

Similarly, Hija 02 told us she didn't tell her mother things that would worry her-yet her mother knew there were problems.

Because I talk to my children and I tell them about my problems to win their trust so that they can tell me about theirs. It's just that sometimes they don't tell me something out of consideration for my feelings ... if something serious happens to them, they don't want to tell me ... but in the end, they tell me ... days later.

(Madre 02)

Although mothers and daughters withheld information to some extent, they read each other quite well. Connection was maintained, even when words were held back.

The telephone was the primary mode of communication. Videotapes of special events and goods transported across the border were infrequent; however, they augmented verbal communication. Mail was unreliable, especially for packages. Women on both sides of the border had a practice of sending things with travelers. I offered to transport small items to and from Mexico. Hijas 01 and 02 sent many small items with me-clothes, a hair dryer, and an iron. Hija 03 sent sweaters, because it was cold where her mother lived, as well as pictures, lipstick, and costume jewelry gleaned from garage sales. What stood out in my mind was one item I would not have anticipated. Into the small bag of goods, Hija 03 stuffed a small, white lace dress. This, she told me, was the dress her daughter wore on her fourth birthday (three years earlier). "At least she can see the dress" (Hija 03).

Support. Emotional and material support between mother and daughter, both past and present, were described by the participants. Madre 02 was very clear on the importance of maternal support throughout life:

What would you like to talk to us about, or what would you like us to know about mothers and daughters? I would like not only you to know, but I would like everyone to know, what I said while talking to another woman one day: "I wish all mothers knew that you shouldn't leave your daughter alone, even when she gets married. You should never leave a daughter alone." They say here in Mexico that once she's married, she's lost. No, a mother should never stop being a mother. A mother should always be concerned about her daughter. Not only concerned about how 
she is economically, although economics are a primary concern so that she is not forced to fall into ... into the lowest thing ... the thing that becomes the easiest thing to do. So I tell you that I wish all mothers knew that a mother should follow her daughter very carefully, very closely, and stay concerned about her daughter and this one and the other one. A mother has to break her heart into many little pieces to be everywhere with all of her children at once. And do you know why? Because if a mother does not take care of her children, they fall. They fall into the worst situations when the mother is not careful. I speak from experience.

With the exception of the flow of some money to Mexico from the daughters to their mothers and some small goods from Mexico to the United States, material support was described as something that occurred when the daughters lived in Mexico. Mothers described providing some economic support to their daughters. However, the material support was primarily described as actions by mothers and daughters. Examples of material support from mothers included activities such as caring for the daughter when she was ill or after childbirth, bringing food, attending school activities, and arranging for work for the daughter. One of the most interesting forms of material support was described by Hija 03: "She would stretch the chicken's necks for me because I don't like to do that." I thought back on this as I sat in her mother's home with a flavorful dish of mole chicken in front of me, as the more fortunate of the flock scratched in the dust near the door.

Material support described by the daughters included helping with household work, protecting mothers from fathers, and participating in companionship activities. Household work centered on food preparation and laundry. Protecting mothers from fathers was described by two of the participants. Hija 01 described how she and her siblings would defend her mother when her father threw furniture around and swore at her mother. Hija 02 also described intervening when her father argued with her mother:

And they would start to scream, and we would just say ... I remember that we would just say, "Here they go again," and my brother would also say, "Here they go again." Oh my God, and then we would have to get up, because my father would be beating my mother. From being asleep, we would have to get up to pull my father off my mother.

Companionship activities included things like going on outings and evening walks. Hija 01 became sad around five o'clock in the evening. When I asked why this was, she told me it was because she and her mother would go "out in the street" walking and visiting at that hour. Hija 02 said, "She [mother] says that ... that she would like me to be with her because, since I always liked to be outside, I would go with her wherever she went."

Emotional support was described as occurring in the past and continuing after migration. Asking questions and listening were important modes of support for both mothers and daughters. Madre 01 said:

That is also why I say to my daughters, I tell them, "Whatever you feel and whatever you think, ask me. That is what a mother is for. So you ask me everything about what you think or what is wrong, just ask me and I tell you."

Hija 02 said that her mother was always there to listen, and she provided her mother with "supportive words."

When asked how their relationships had changed since their daughters had migrated, participants universally responded that they had not. Emotional support was maintained primarily by telephone. Both mothers and daughters indicated that, at first, talking on the phone was quite difficult because it made them sad. Over time, the sadness subsided, and talking on the phone became a pleasant experience. One important change in emotional support was that, with the exception of Hija 01, all of the participants said that in order to avoid worry, they did not cry or reveal the problems in their lives on the phone.

\section{Discussion}

Findings from this study describe how the motherdaughter bond continues to be a source of support for Mexican women who have migrated to the United States. The importance of the mother-daughter relationship as a source of support is of particular interest when the relationship between loss of social support and depression are considered. "No confidant support" has been found to be a predictor of distress in immigrant women of Mexican descent (Vega, Kolody, Valle, \& Hough, 1986). In further analysis, Vega, Kolody and Valle found confidant support to have a strong negative association with depressive symptoms (Vega, Kolady, \& Valle, 1986). Aranda, Castaneda, Lee, and Sobel (2001) also found lower social support from a spouse or parent to be a significant predictor of depression for women in this population.

Narrative data from mother-daughter Dyad 01 indicate that a mother's support during pregnancy and childbirth can be very important for Mexican women. The impact of the loss of this support is keenly heard in the interview with Hija 01 as she contrasts her experience with la 
cuaranteña (traditional 40-day postpartum rest period) in Mexico and her postpartum experience in the United States. Laganá (2003) found that maternal grandmothers were the most important source of social support for a woman during pregnancy and during the postpartum period. Although la cuaranteña is less commonly practiced in urban settings in Mexico, it remains an important practice in more rural areas. As the impact of globalization makes survival by subsistence farming more difficult, women from more remote areas of Mexico are migrating to the United States with the men in their lives. Awareness of the importance of the custom of la cuaranteña in women's lives is critical in the provision of culturally appropriate care to women during pregnancy and childbirth.

The present study contributes to cultural understanding by suggesting that two periods in a woman's life, immediately after migration and during pregnancy/postpartum, are times when separation from her mother may add to the risk of social isolation and, possibly, depression. Because material support is the most difficult to maintain across the border, mothers and daughters whose relationships are characterized by material support, or who are unable to establish material support after migration, are at particular risk for problems related to loss of support. When working within this culture, it is important to assess the availability of material support and to facilitate development of material support when it has been weakened or lost in migration. Connecting women with any forum in which women spend time together can be helpful. I have found that women's groups sponsored by churches or social service agencies are helpful in establishing supportive relationships with other women in the United States.

\section{Conclusion}

Findings from this study suggest that the mother-daughter bond between Mexican women and their daughters in the United States remains strong after migration. Although some aspects of the bond changes, the mother-daughter connection continues to influence lives and provide emotional and, to a more limited extent, material support in the lives of mothers and daughters. This research provides insight into the range of possible relational stories between Mexican mothers and their daughters. It supports the importance of including assessment of this particular relationship when evaluating a woman's support network, especially during the immediate postmigration period and during pregnancy and postpartum periods. A comprehensive understanding of the nature and function of motherdaughter support across borders is an important dimension of support system assessment when working with women from Mexico who are residing in the United States.

\section{References}

Aranda, M. P., Castaneda, I., Lee, P., \& Sobel, E. (2001). Stress, social support, and coping as predictors of depressive symptoms: Gender differences among Mexican Americans. Social Work Research, 25(1), 37-48.

Associated Press. (2003, January 22). Hispanics become largest U.S. minority. Chicago Tribune, p. 3.

Bastida, E. (2001). Kinship ties of Mexican migrant women on the United States/Mexico border. Journal of Comparative Family Studies, 32(4), 549-569.

Belknap, R. A., \& Sayeed, P. (2003). Te contariá mi vida: I would tell you my life, if only you would ask. Healthcare for Women International, 24, 723-737.

Durand, J., \& Massey, D. S. (2004). Crossing the border: Research from the Mexican Migration Project. New York: Russell Sage Foundation.

Falicov, C. J. (1998). Latino families in therapy: A guide to multicultural practice. New York: Guilford Press.

Falicov, C. J. (2001). The cultural meanings of money: The case of Latinos and Anglo-Americans. American Behavioral Scientist, 45(2), 313-327.

Hahn-Smith, A. M., \& Smith, J. E. (2001). The positive influence of maternal identification on body image, eating attitudes, and selfesteem of Hispanic and Anglo girls. International Journal of Eating Disorders, 29(4), 429-440.

Jones, M. E. (2002). International partnership in culture and health: Immigration and health: Macro and micro perspectives. Journal of Multicultural Nursing \& Health, 8(2), 6-9.

Laganá, K. (2003). Come bien, camina y no se preocupe-Eat right, walk, and do not worry: Selective biculturalism during pregnancy in a Mexican American community. Journal of Transcultural Nursing, 14(2), 117-124.

Marsiglia, F. F., \& Holleran, L. (1999). I've learned so much from my mother: Narratives from a group of Chicana high school students. Social Work in Education, 21(4), 220-237.

Rastogi, M. (2002). The mother-adult daughter questionnaire (MAD): Developing a culturally sensitive instrument. Family Journal: Counseling and Therapy for Couples and Families, 10(2), 145-155.

Rastogi, M., \& Wampler, K. S. (1999). Adult daughters' perceptions of the mother-daughter relationship: A cross-cultural comparison. Family Relations, 48(3), 327-336.

Sherraden, M. S., \& Barrera, R. E. (1996). Maternal support and cultural influences among Mexican immigrant mothers. Families in Society: The Journal of Contemporary Human Services, 77(5), 298-312.

Vega, W. A. (1990). Hispanic families in the 1980s: A decade of research. Journal of Marriage and the Family, 52, 1015-1024.

Vega, W. A., Kolody, B., \& Valle, J. R. (1986). The relationship of marital status, confidant support, and depresión among Mexican immigrant women. Journal of Marriage and the Family, 48, 597-605.

Vega, W. A., Kolody, B., Valle, R., \& Hough, R. (1986). Depressive symptoms and their correlates among immigrant Mexican women in the United States. Social Science \& Medicine, 22(6), 645-665.

Ruth Ann Belknap, PhD, PMHCNS-BC, is assistant professor, College of Nursing, Marquette University. Correspondence regarding this article may be sent to ruth.belknap@marquette.edu or Marquette University, College of Nursing, P.O. Box 1881, Milwaukee, WI 53201-1881.

Author's note. Research partially funded by Beta Omega Chapter grant, Sigma Theta Tau International. The researcher is grateful to the participants who so willingly shared the stories of their lives with me.

Manuscript received: January 10, 2007

Revised: August 30, 2007

Accepted: August 31, 2007 